\title{
EDITORIAL
}

\section{La revista científica evoluciona para adecuarse a estos nuevos tiempos}

Ya en 1.950, el gran biólogo y naturalista Charles Darwin nos indicaba las evidencias que presentaban las especies para poder sobrevivir, debían evolucionar y adaptarse a las condiciones del medio en el que vivían, como si tuvieran características acordes a sus necesidades. Entre las enseñanzas que Darwin nos dejó, destaca el hecho de que realmente la evolución existe y que la vida es algo dinámico: "Las especies no se mantienen estáticas en el tiempo, sino que van evolucionando y que la selección natural es el mecanismo que permite dicha evolución».

Así como, las especies evolucionan en el tiempo para no extinguirse o desaparecer, la Revista Científica (RC) de la Facultad de Ciencias Veterinarias (FCV) de la Universidad del Zulia (LUZ), se adecua a estos nuevos tiempos que se viven en nuestro país. Venezuela durante estas dos últimas décadas, ha atravesado por la peor crisis política, económica y social que se haya vivido en esta nación; la más desbastadora desde mediados del siglo XX de un país que no está experimentando una guerra, más grave que la gran depresión en los Estados Unidos, peor que la crisis económica de 1985-1994 de Brasil o que la crisis hiperinflacionaria en Zimbabue de 2008-2009. Diversos investigadores han comparado aspectos de la crisis, como el desempleo y la contracción del PIB, con la posguerra de Bosnia y Rusia, Cuba y Albania tras el colapso de la Unión Soviética. Marcada por una fuerte hiperinflación, sueldos de $\$ 10$ mensuales, aumento de la pobreza, reaparición de enfermedades erradicadas, delincuencia e incremento de la mortalidad, trayendo como resultado una emigración masiva del país y a esto le sumamos la pandemia del COVID-19.

Todos estos elementos han repercutido en todos los aspectos de la vida del venezolano, y la $R C$ de la FCV-LUZ no ha sido la excepción a esta crisis; no obstante, el gran equipo de edición se ha negado rotundamente a permitir que desaparezcan más de 30 años de trabajo que han rendido frutos, logrando obtener más de 21 reconocimientos en índices nacionales e internacionales. Dicha evolución ha pasado en primer lugar por cambiar el formato físico, por un nuevo formato digital, más adelante se cambió la cantidad de números anual a partir de 2020 y ahora en 2021, nos abrimos a un sistema más interactivo entre los investigadores y nuestra revista, mediante la creación de un COMITÉ DE EDITORES POR SECCIONES, que nos permitirá una más temprana respuesta a las autores y más rápida decisión del arbitraje. Los artículos continuarán siendo de acceso abierto (open access), y estará gratuitamente abierta para el mundo científico, sin la necesidad de ningún tipo de suscripción. No obstante, a partir de este año se solicitará un pequeño aporte de los autores o instituciones, para procesamiento de artículos (APC Article Processing Charge), incorporando nuevas herramientas tecnológicas e identificadores tales como el ORCID y CrossRef, buscando promover y mejorar la comunicación y la investigación científica, a través de una mejora en la identificación de nuestras publicaciones.

\section{¡Evolucionamos para no extinguirnos!}

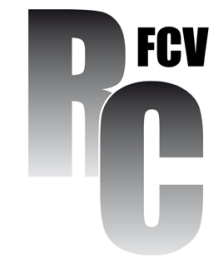

Dr. José Atilio Aranguren-Méndez

Miembro del Comité de Editores 